\title{
Parental practice of child car safety in Enugu, Southeast Nigeria
}

This article was published in the following Dove Press journal:

Pediatric Health, Medicine and Therapeutics

10 November 2016

Number of times this article has been viewed

\section{KI Ndu',* \\ U Ekwochi ${ }^{1, *}$ \\ DC Osuorah $2, *$ \\ OC Ifediora $^{3}$ \\ FO Amadi' \\ IN Asinobi' \\ OW Okenwa' \\ JC Orjioke' \\ FN Ogbuka' \\ TO Ulasi ${ }^{4}$}

'Department of Paediatrics, Enugu State University of Science and Technology, Enugu State, Engu, Nigeria; ${ }^{2}$ Child Survival Unit, Medical Research Council UK, The Gambia Unit, Fajara, Gambia; ${ }^{3}$ Griffiths University Medical School, Gold Coast, QLD, Australia; ${ }^{4}$ Department of Paediatrics, Nnamdi Azikiwe University Teaching Hospital, Nnewi, Anambra State, Nigeria

*These authors contributed equally to this work
Correspondence: DC Osuorah Child Survival Unit, Medical Research Council UK, The Gambia Unit, 273 Atlantic Boulevard, Fajara, Gambia Email chidi.osuorah@yahoo.com

\begin{abstract}
Child safety restraints and seat belts are regarded as the most successful safety and cost-effective protective devices available to vehicle occupants, which have saved millions of lives. This cross-sectional descriptive study evaluated the practice and use of child car restraints (CCRs) among 458 purposively selected respondents resident in two local government areas in Enugu State, Nigeria. Self-administered questionnaires were sent to parents of children attending private schools who owned a car. Chi-square and multivariate analyses were used to assess the determinants of the use of car restraints in children among respondents. In all, $56 \%$ and $45 \%$ of adults and children, respectively, used car restraints regularly. The awareness of child safety laws and actual use of age-appropriate CCRs among respondents was negatively and weakly correlated ( $r=-0.121, P=0.310)$. Only respondent's use of seat belt during driving $(P=0.001)$ and having being cautioned for non-use of CCRs $(P=0.005)$ maintained significance as determinants of the use of CCRs in cars on multivariate analysis. The most frequent reasons given for the non-use of CCRs included the child being uncomfortable, 64 (31\%); restraints not being important, 53 (26\%), and restraints being too expensive, 32 (15\%). Similarly, for irregular users, exceptions for non-use included the child being asleep (29\%), inadequate number of CCRs (22\%), and the child being sick (18\%). There is a need for a strategy change to enforce the use of CCRs in Nigeria.

Keywords: car restraints, children, safety, Enugu
\end{abstract}

\section{Introduction}

Deaths due to road traffic accidents (RTAs) are a leading cause of mortality globally ${ }^{1}$ and a major public health issue, especially in Sub-Saharan Africa where poor road maintenance is a norm. ${ }^{2}$ According to the World Health Organization, $\sim 1.2$ million people died each year in road accidents globally with $>50$ million injured. ${ }^{1}$ More than $95 \%$ of these deaths and injuries occur in low- and middle-income countries, ${ }^{1}$ and children account for $21 \%$ of all road traffic injury-related deaths. ${ }^{3}$ Despite the global reduction in road traffic fatalities, deaths associated with road accidents have increased between $50 \%$ and $100 \%$ in low-income and middle-income countries and are projected to increase by $83 \%$ by 2020 in these countries. ${ }^{1}$

The use of seat belts and other child car restraints (CCRs) has been shown to minimize injuries and fatalities in the event of an RTA. ${ }^{4}$ The failure to use seat belts and other restraints has been documented as a major risk factor for higher likelihood of life-threatening injuries and associated mortality in RTAs. An epidemiological review $^{4}$ on the effectiveness of seat belts in RTAs conducted with data from the USA and Europe concluded that seat belts and other car restraints are highly effective in 
protecting vehicle occupants and significantly reduce their risk of fatal and/or serious injuries in a crash. However, the National Highway Traffic Safety Administration (NHTSA) in a nationally representative survey reported CCR use rate of $94 \%$ and an estimated overall CCR misuse of $46 \% .{ }^{5}$ Thus, despite the high use of car restraints, misuse (defined as a characteristic of installing a CCR or of restraining the child in a CCR that may reduce the protection of the CCR in the event of a crash) is still an ongoing concern in the USA.

In Nigeria, a hospital-based study of 140 passengers involved in RTAs over a period of 6 months showed that mortalities and injuries recorded were significantly lower in those who used car restraints compared to those who did not use them during travels. ${ }^{6}$ Another study in the Southwest Nigeria documented $>50 \%$ of deaths among children involved in motor vehicle accidents. ${ }^{?}$

The World Health Organization has identified proper use of seat belts and child restraints as one of the five key interventions for safer roads. ${ }^{8}$ It recommends the use of conventional seat belts in adults and children older than 12 years and CCRs in younger children. ${ }^{1}$ The variety of CCRs for younger children include the rear-facing car restraint system for group 0 or $0+$ passengers (i.e., infants under 1 year), front-facing car restraint system for group I and II passengers (1-5 years) and booster seat for group III passengers (ages of 6-12 years). Despite these recommendations, several studies have reported low usage of seat belts and other car restraints. ${ }^{9-11}$ There is a need for continued evaluation on the use of seat belts and CCRs to inform policies to curb the rising incidence of fatalities in RTAs, particularly in developing countries.

There is a dearth of information concerning the use of CCRs in Nigeria. This study assessed the use of these restraints in cars among parents in Enugu State of Southeast Nigeria.

\section{Methodology Study area}

This study was conducted in two local government areas (LGAs), namely, Enugu North and Enugu South of Enugu State. Enugu State is located on latitude $6^{\circ} 27^{\prime} \mathrm{N}$ and longitude $7^{\circ} 30^{\prime} \mathrm{E}^{12}$ It is made up of 17 LGAs with its capital carved from Enugu North, Enugu South and Enugu East LGAs. The majority of the inhabitants are Igbo by tribe, and Christianity is the dominant religion. The minimum monthly income, similar to the national average, is 18,000 (US\$110). Literacy rate is $66 \%$, fertility rate is 4.5 births/ woman and the male to female ratio is $1: 1 .{ }^{13}$

\section{Study design and population}

This cross-sectional descriptive study, which was carried out over a 6-month period, involved parents of children in six schools with nursery and primary sections selected from two LGAs of Enugu. Only private schools with relatively higher population of children from well-off families were involved in this study. This was purposively done in order to enroll children whose parents owned a car. Multistaged sampling technique was used in selection of participating parent-pupil dyad. First, simple balloting was used to select three private schools from LGAs of Enugu North and Enugu South. Convenience sampling method was consequently used to select from each class pupil enrolled in the study. In each school, 15-18 questionnaires were distributed per class (depending on the number of class levels within the school). Thus, in every school, a total of 90 questionnaires and consent forms with instructions on answering the questions were distributed to the pupils. Each school was approached for consent through the head teacher and school proprietor(s).

\section{Data collection}

Structured questionnaires accompanied by informed consent forms were sent to parents of selected pupils through their children. The questionnaires were self-administered by parents of selected pupils. Information regarding respondent's age, age of children, occupation and highest educational attainment of respondents and their spouse and socioeconomic class of household was obtained and appropriately categorized as follows: 1) Age of respondents was categorized as $<25$ years, 26-30 years, 31-35 years and $>35$ years. 2) Highest educational attainment of respondents and their spouse was categorized as "none" for those without any formal education, "primary school" for those who completed 6 years of education, "secondary" for those who completed 12 years of education and "university" for those undertaking or have completed a tertiary education. 3) Occupation was grouped into "senior grade" for respondents working at the senior level and/or skilled professionals such as lecturers, doctors, directors, matrons and bankers; "intermediate grade" for senior school teachers, nurses, civil servants and clerks; "low grade" for primary school teachers, petty traders and low-scale farmers and "unemployed" for housewives and students. 4) Age of children was categorized as $<2$ years, 2-4 years and 5-12 years. 5) Socioeconomic class was computed from the parental education and occupation variable using the Oyedeji's formula and classification. ${ }^{14}$ This was then categorized as upper, middle and low socioeconomic classes. 6) Additional information was also collected on respondents' 
use of seat belts and frequency of use during driving, use of CCRs and frequency of use, awareness of child road safety laws and knowledge of age-appropriate CCRs, knowledge of correct seat belt strapping for older children, etc.

\section{Data analysis}

The Predictive Analytics Software Statistics 19.0 statistical package was used for data analysis. The Pearson's chi-square $\left(\chi^{2}\right)$ and Fischer's exact tests, where appropriate, were used to study the association between respondents' sociodemographic factors and use of CCRs. Multivariate regression analysis was used to determine predictors of use of CCRs. The results were calculated and presented in percentages. For all statistical tests performed, it was ensured that the assumptions for carrying out these specific tests were met. Statistical significance was set at $P$-value $<0.05$.

\section{Ethical consideration}

Ethical clearance for this study was obtained from the Enugu State University Teaching Hospital. School proprietors and head teachers also gave written informed consent before questionnaires were distributed to parents via their children. Written informed consent was obtained from every respondent through consent letters written in layman's terms to ensure understanding. The participation in the study was entirely voluntary, and no financial inducement whatsoever was involved. Voluntary withdrawal at any stage of interaction was guaranteed for all participants without any adverse effect on the respondents or their children. All information was handled with strict confidentiality.

\section{Results}

\section{Characteristics of respondents}

The schools surveyed had a mean foundation age of 18 years and an average pupil's population of $\sim 477$ per school. Of the 540 questionnaires distributed, 82 respondents did not return questionnaires or returned grossly incomplete information and were not included in the final analysis. This gave the final sample size of 458 respondents and a response rate of $85 \%$. All respondents owned at least one car. A majority of the respondents assessed were in the age category of 26-35 years (37\%) and 36-45 years (37\%) with slightly over two-thirds being females $(68 \%)$ and married $(72 \%)$. The respondents had children with age ranging from 1 month to 12 years. The age of the index child was $<2$ years in $19(5 \%), 2-4$ years in $54(13 \%)$ and $5-12$ years in $338(82 \%)$ respondents. The vast majority of these children, 378 (84\%), were from households in the upper socioeconomic class, while the remaining 41
(9\%) and 31 (7\%) were from the middle and lower socioeconomic classes, respectively. Table 1 lists other characteristics of respondents enrolled in this study.

\section{Use of car seat and CCRs among respondents}

A total of $401(88 \%)$ of 454 respondents indicated that they use seat belts during driving, while $53(12 \%)$ did not use seat belts at all when driving. In all, $56 \%$ of the 401 respondents who used seat belts used it regularly, 19\% used it most times, $22 \%$ used it sometimes, and 3\% used it infrequently when driving. Two-thirds (63\%) of 450 respondents traveled with their child(ren) at least five to seven times a week, 139 (31\%) traveled with them two to four times a week, and $27(6 \%)$ traveled with them less than twice a week (rare).

Of the 441 respondents, 261 (59\%) made use of CCRs for their children aged 18 months-12 years when driving, while $180(41 \%)$ did not. For those who used CCRs, 117/259 (45\%) used them always, 87/259 (34\%) used them most times, $52 / 259(20 \%)$ used them sometimes, and $3(1 \%)$ used them rarely. The most common restraint used was the car seat for children with seat belt in 178/228 (78\%) respondents.

Other CCRs used were booster seats in 10/228 (4\%) respondents and combination of car seat for children and booster seat in 40/228 (18\%) respondents. Inquiries into knowledge of age-appropriate CCRs for children revealed that equal proportion of respondents, 128/255 (50\%), were aware and not aware of the different car restraints for various age groups. In all, 59/114 (52\%), 58/94 (62\%) and 32/100 $(32 \%)$ respondents used age-appropriate CCRs for their children in the age categories of $\leq 2$ years, 2-4 years and 5-12 years, respectively.

Apart from the respondents, other people who drove the respondent's children included spouse 170/386 (44\%), paid drivers 128/386 (33\%), public drivers 58/386 (15\%), and others 30/386 (8\%), which included siblings, friends, grandparents, etc. Only 221 (57\%) of these respondents enquired to ensure that a CCR was used when their children were driving with other people. In all, 39\% (170/442) and $19 \%(84 / 448)$ respondents, respectively, believed that an adult carrying a child with or without restraint was acceptable and a child occupying the front seat of a motor vehicle was appropriate provided he/she wears a seat belt. A total of $300(68 \%)$ respondents were of the opinion that children $\geq 5$ years no longer needed a booster seat once the car seat belt fits them properly. For proper seat belt application on an older child, 41\% (252/614), 35\% (216/614), 17\% (103/614), and $7 \%(43 / 614)$ felt that the belt should strap firmly around 
Table I Respondents and car-safety description summary

\begin{tabular}{|c|c|c|c|}
\hline Respondents' variables & Frequency, n (\%) & Car-safety variables & Frequency, n (\%) \\
\hline Age of respondents (years) & $\mathrm{n}=433$ & Do you use seat belt while driving & $\mathrm{n}=454$ \\
\hline$\leq 25$ & $42(10)$ & Yes & $40 \mathrm{I}(88)$ \\
\hline $26-35$ & $159(37)$ & No & $53(12)$ \\
\hline $36-45$ & $162(37)$ & How often & $\mathrm{n}=40 \mathrm{I}$ \\
\hline$>45$ & $70(16)$ & Always & $225(56)$ \\
\hline Sex of respondents & $\mathrm{n}=444$ & Most times & $76(19)$ \\
\hline Male & $144(32)$ & Sometimes & $88(22)$ \\
\hline Female & $300(68)$ & Rarely & $12(3)$ \\
\hline Age of index child (years) & $\mathrm{n}=4 \mathrm{II}$ & Use of car restraint for children while driving & $\mathrm{n}=442$ \\
\hline $2-4$ & $54(13)$ & No & $\mid 80(4 \mid)$ \\
\hline $5-12$ & $338(82)$ & How often & $\mathrm{n}=259$ \\
\hline Paternal education & $\mathrm{n}=456$ & Always & II7 (45) \\
\hline Completed university & $346(76)$ & Most times & $87(34)$ \\
\hline Completed secondary & $74(16)$ & Sometimes & $52(20)$ \\
\hline Completed primary & $22(5)$ & Rarely & $3(1)$ \\
\hline None & $14(3)$ & Type of child restraint used & $\mathrm{n}=228$ \\
\hline Maternal education & $\mathrm{n}=458$ & Child seat (rear facing) & $59(26)$ \\
\hline Completed university & $337(74)$ & Child seat (forward facing) & $99(43)$ \\
\hline Completed secondary & $70(15)$ & Child seat (convertible) & $20(9)$ \\
\hline Completed primary & $37(8)$ & Booster seat & $10(4)$ \\
\hline None & $14(3)$ & Both child seat and booster seat & $40(18)$ \\
\hline Paternal occupation & $\mathrm{n}=455$ & Awareness of child car-safety laws & $\mathrm{n}=448$ \\
\hline Senior grade & $310(68)$ & Yes & $253(57)$ \\
\hline Intermediate grade & $88(19)$ & No & $195(43)$ \\
\hline Low grade & $49(11)$ & Source of information & $\mathrm{n}=258$ \\
\hline Unemployed & $8(2)$ & Internet & $14(5)$ \\
\hline Maternal occupation & $\mathrm{n}=452$ & Health/safety workers & $4(2)$ \\
\hline Senior grade & $214(47)$ & Road safety officer & |5| (57) \\
\hline Intermediate grade & $115(26)$ & Social interaction & $21(8)$ \\
\hline Low grade & $63(14)$ & Intuition & $25(9)$ \\
\hline Unemployed & $60(13)$ & General reading & $4(2)$ \\
\hline Household socioeconomic class & $\mathrm{n}=450$ & Ever cautioned for child car-safety offense & $\mathrm{n}=448$ \\
\hline High & $378(84)$ & Yes & $155(35)$ \\
\hline Middle & $4 I(9)$ & No & $293(65)$ \\
\hline Low & $31(7)$ & & \\
\hline
\end{tabular}

the stomach, chest, thigh and neck, respectively (note that multiple responses were permitted).

Slightly over half of the respondents, 253/448 (57\%), were aware of laws in Nigeria against traveling with unrestrained children. The sources of information were road safety officers $(57 \%)$, electronic media (15\%), intuition $(9 \%)$, and social interaction (8\%). Other sources included Internet (5\%), health/safety officer ( $2 \%)$, and general reading (2\%). One-third of all the respondents, 34\% (155/448), had been cautioned at least once for non-use of CCR for their children while driving. The awareness of child safety laws and use of age-appropriate CCR among respondents were negative and weakly correlated $(r=-0.121, P=0.310)$. For the $180 / 442(41 \%)$ respondents who did not use a CCR for their children, reasons given for the non-use included the following: no knowledge of the importance of CCR use in children, 27/208 (13\%); not important, 53/208 (26\%); too expensive, 32/208 (15\%); discomfort, 64/208 (31\%); and others, 31/208 (15\%); (note that multiple responses were permitted). Other responses comprised do not remember, use of rear seat for children, no CCR in the car, and no reasons. Similarly, the 142 respondents who did not use car restraint on their children regularly gave the following exceptions to the use of CCRs: the child is asleep (29\%), inadequate number of CCRs $(22 \%)$, sick child (18\%), night travels (13\%), short trips $(13 \%)$, and others (5\%; Figure 1$)$.

\section{Use of CCRs and respondents' sociodemographic characteristics}

Table 2 shows analysis relating to the use of CCRs and the sociodemographic variables of respondents considered in this study. Paternal education $(P=0.001)$, maternal education $(P=0.001)$, paternal occupation $(P=0.001)$, maternal occupation $(P=0.001)$, household socioeconomic class $(P=0.001)$, 


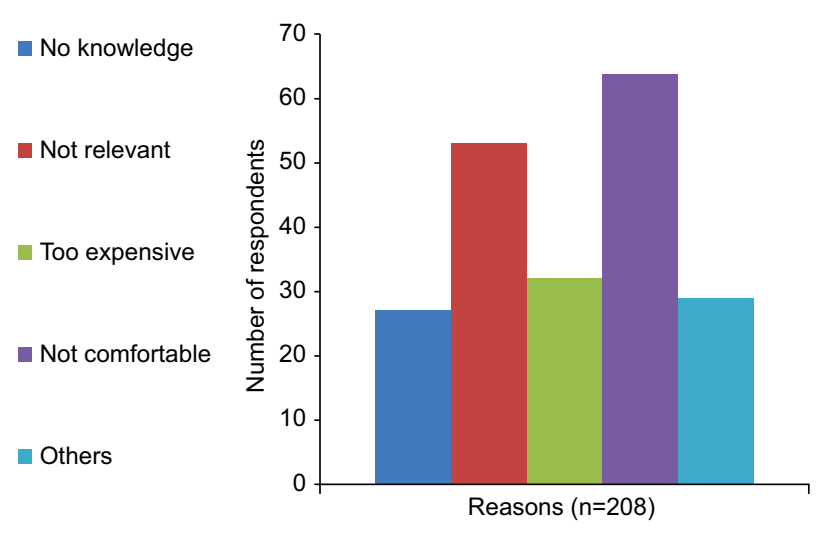

Figure I Reasons and exceptions to non-use of CCRs among respondents. Abbreviation: CCR, child car restraint.

respondents' use of seat belts $(P=0.001)$, knowledge of child safety laws $(P=0.001)$ and previous caution for non-use of CCRs $(P=0.001)$ were all significantly associated with the use of CCRs. However on multivariate logistic regression analysis, only use of seat belt during driving $(P=0.001)$ and previous caution for the non-use of CCRs $(P=0.005)$ were retained as significant predictors of use of CCRs among respondents in this study.

The respondents who used seat belts while driving were $\sim 4.7$ times more likely to use CCRs for their children compared to those who did not use seat belts on themselves during driving (odds ratio [OR] 4.67, confidence interval [95\% CI] 1.82-12.0). Also, those who had been cautioned for not using CCRs while driving with their children were 0.4 times less likely to use CCRs compared to those who had never been cautioned for related offenses (OR 0.44, [95\% CI] 0.25-0.78). In other words, it was 2.7 times more likely for respondents who had not been questioned for child car-safety offenses to use CCRs compared to those who had been cautioned for similar offenses.

\section{Discussion}

The study showed poor use of seat belts and CCRs among respondents. It was noted that the use of CCRs correlated positively with respondents' use of seat belts but negatively with the awareness of child safety laws. This knowledgepractice discrepancy was also reported in a similar study in Nova Scotia, Canada, which showed marked inconsistency between knowledge and practice of use of rear-seating and booster seats for older children. ${ }^{15}$ It is evident from these findings that awareness and knowledge do not equate to practice. Inferentially, parents and caregivers have not fully understood the critical importance of the use of CCRs and the disastrous consequences they could prevent in the event of a road accident. ${ }^{16,17}$ Data from the road safety agency in

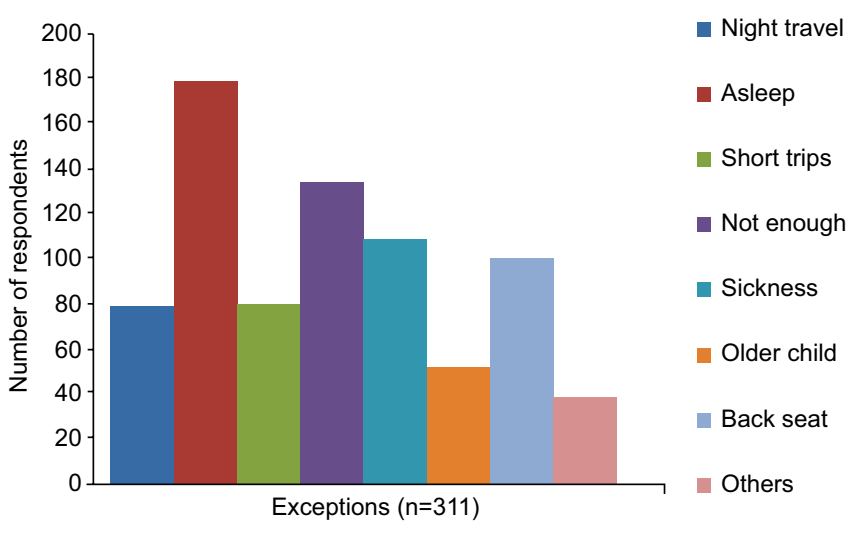

Nigeria revealed 6,450 deaths resulting from road accidents in 2013 and a seat-belt wearing rate of $<1 \%$ by children, ${ }^{18}$ while in the US, $>650$ children at the age of 12 years or younger died as occupants in motor vehicle crashes in 2011 alone and $33 \%$ of them did not have CCRs on them. ${ }^{19}$

The study further noted that the use of seat belts was an important determinant of the use of CCRs. This is not surprising, as intuitively, it is expected that safety conscious people who use seat belts habitually while driving will most probably ensure that the same routine is applied to their passengers. This finding agrees with the result of a survey of 1,069 drivers in Shantou, People's Republic of China, ${ }^{20}$ which reported that drivers' use of seat belt was associated with a four times likelihood of the use of CCRs (OR 4.00, 95\% CI 2.56, 6.25). Similarly, Olufunlayo et $\mathrm{al}^{21}$ in 2011 identified driver's seat belt wearing habit as one of the factors associated with CCR use.

Additionally, our study found a higher probability of nonuse of CCRs among respondents who had been previously cautioned for non-use of appropriate CCRs. This may be related to the practice of verbal warning and zero penalties currently in practice by the road safety officers. This is so because the non-use of car restraints for children is a nonbookable offense in Nigeria. This is in contrast to a fine of \$2000 ( US\$10) levied against adult drivers or passengers for non-use of seat belts. ${ }^{22}$ This practice may probably account for the reason why offenders may more likely repeat same offense, thus reinforcing the wrong practice of not using CCRs. With Nigeria ranking second highest in the rate of road accidents among 193 countries, accounting for the highest fatality rate of $33.7 \%$ per 100,000 population every year, ${ }^{23}$ it is important that more stringent steps are taken to enforce the use of CCRs.

Finally, the various reasons and exceptions respondents gave to justify their non-use of CCRs were based on parental misconceptions, which were not entirely correct. Similar 
Table 2 Association and predictors of use of CCRs among respondents

\begin{tabular}{|c|c|c|c|c|c|}
\hline \multirow[t]{2}{*}{ Variables } & \multicolumn{3}{|c|}{ Use of CCRs } & \multicolumn{2}{|l|}{ Adjusted OR } \\
\hline & Yes, n (\%) & No, n (\%) & $P$ & OR (95\% Cl) & $P$ \\
\hline \multicolumn{6}{|l|}{ Age of respondents (years) } \\
\hline$\leq 25$ & $23(64)$ & $13(36)$ & 0.855 & $0.42(0.12-1.51)$ & 0.185 \\
\hline $26-35$ & $86(57)$ & $65(43)$ & & $0.97(0.43-2.19)$ & 0.936 \\
\hline $36-45$ & $92(58)$ & $66(42)$ & & $1.24(0.58-2.64)$ & 0.577 \\
\hline$>45$ & $4 I(6 I)$ & $26(38)$ & & 1 & \\
\hline \multicolumn{6}{|l|}{ Sex of respondents } \\
\hline Male & $72(54)$ & $62(46)$ & 0.090 & $1.23(0.68-2.19)$ & 0.490 \\
\hline Female & $181(62)$ & $109(38)$ & & I & \\
\hline \multicolumn{6}{|l|}{ Marital status } \\
\hline Currently married & $195(6 \mathrm{I})$ & 124 (39) & 0.179 & 1 & \\
\hline Not currently married & $66(54)$ & $56(46)$ & & $1.07(0.57-2.03)$ & 0.833 \\
\hline \multicolumn{6}{|l|}{ Age of index child (years) } \\
\hline$<2$ & $10(56)$ & $8(44)$ & 0.672 & $0.88(0.2 \mathrm{I}-3.70)$ & 0.879 \\
\hline $2-4$ & $28(55)$ & $23(45)$ & & $0.96(0.26-3.52)$ & 0.964 \\
\hline $5-12$ & $203(6 I)$ & $128(38)$ & & 1 & \\
\hline \multicolumn{6}{|l|}{ Paternal education } \\
\hline Completed university & $220(66)$ & II 5 (34) & 0.001 & I & \\
\hline Completed secondary & $24(36)$ & $43(64)$ & & $3.07(0.36-6.95)$ & 0.070 \\
\hline Completed primary & $5(28)$ & $13(72)$ & & $5.5 I(0.23-13.0)$ & 0.291 \\
\hline None & $5(36)$ & $9(64)$ & & $1.28(0.05-35.4)$ & 0.885 \\
\hline \multicolumn{6}{|l|}{ Maternal education } \\
\hline Completed university & $209(66)$ & $118(36)$ & 0.001 & I & \\
\hline Completed secondary & $33(49)$ & $34(5 \mathrm{I})$ & & $0.81(0.35-1.86)$ & 0.610 \\
\hline Completed primary & $9(30)$ & $21(70)$ & & $0.56(0.11-2.79)$ & 0.481 \\
\hline None & $7(50)$ & $7(50)$ & & $0.10(0.07-1.36)$ & 0.083 \\
\hline \multicolumn{6}{|l|}{ Paternal occupation } \\
\hline Senior grade & $197(56)$ & $102(34)$ & 0.001 & I & \\
\hline Intermediate grade & $39(46)$ & $45(54)$ & & $1.10(0.50-2.41)$ & 0.811 \\
\hline Low grade & $16(36)$ & $28(64)$ & & $1.62(0.43-6.09)$ & 0.478 \\
\hline Unemployed & $2(29)$ & $5(7 I)$ & & $9.36(0.28-31.2)$ & 0.212 \\
\hline \multicolumn{6}{|l|}{ Maternal occupation } \\
\hline Senior grade & $136(66)$ & $70(34)$ & 0.001 & I & \\
\hline Intermediate grade & $69(62)$ & $42(38)$ & & $1.20(0.6 \mathrm{I}-2.38)$ & 0.594 \\
\hline Low grade & $20(35)$ & $37(65)$ & & $1.60(0.6 \mathrm{I}-4.22)$ & 0.344 \\
\hline Unemployed & $29(50)$ & $29(50)$ & & $1.31(0.55-3.14)$ & 0.541 \\
\hline \multicolumn{6}{|c|}{ Household socioeconomic index } \\
\hline High & $232(64)$ & $133(36)$ & 0.001 & 1 & \\
\hline Middle & $12(31)$ & $27(69)$ & & $2.23(0.49-9.99)$ & 0.293 \\
\hline Low & $8(3 I)$ & 18 (689) & & $1.09(0.02-51.5)$ & 0.965 \\
\hline \multicolumn{6}{|c|}{ Do you use seat belt while driving? } \\
\hline Yes & $249(64)$ & $|4|(36)$ & 0.001 & $4.67(1.82-12.0)$ & 0.001 \\
\hline No & $12(24)$ & $38(76)$ & & 1 & \\
\hline \multicolumn{6}{|c|}{ Knowledge of child safety laws } \\
\hline Yes & $166(68)$ & $80(32)$ & 0.001 & $1.5(0.88-2.56)$ & 0.136 \\
\hline No & $86(48)$ & $95(52)$ & & $\mathrm{I}$ & \\
\hline \multicolumn{6}{|c|}{ Penalized for child car-safety offense } \\
\hline Yes & $110(72)$ & $42(28)$ & 0.001 & $0.44(0.25-0.78)$ & 0.005 \\
\hline No & $144(52)$ & $132(48)$ & & $\mathrm{I}$ & \\
\hline
\end{tabular}

Note: $P$-values in bold indicate statistical significance.

Abbreviations: $\mathrm{OR}$, odds ratio; $\mathrm{Cl}$, confidence interval.

reasons were reported in the US by the NHTSA. ${ }^{23}$ In their survey, respondents defended their non-use of CCRs with the following reasons: child stays short time in the car (39\%), child does not like it (38\%), being in a rush $(25 \%)$, and no CCRs in the vehicle (28\%). Other reasons included child would not stay in restraints $(25 \%)$, child too big (19\%), and no space in the car for CCRs (16\%). Contrary to the findings of this study were the findings that a majority of respondents' source of information on child safety law was from the federal road safety officers and most of 
the respondents in the US survey learnt about child safety information from television (68\%), childcare books (62\%), and healthcare workers $(63 \%)$, with only $2 \%$ getting the information from safety hotlines. ${ }^{24}$ These differences in information sources may be related to the differences in the availability of electronic media and reading habits of people in the two study settings.

\section{Limitation}

Being a cross-sectional study, misinformation due to recall or response bias may have led to misclassification in some variables explored in this study. Furthermore, like every cross-sectional study, the limitation of reverse causation makes it difficult to say with certainty if the use or non-use of CCRs was preceded by other events not considered in this study. It is therefore recommended that the findings of this study be interpreted in the light of these limitations.

\section{Conclusion}

Despite the limitations, it is evident that the use of CCRs in Enugu is poor. In order to surmount the problem of low usage and/or non-use of CCRs, emphasis should be shifted from mere dissemination of information on importance of CCRs and cautioning of offenders to empirically enforcing stricter penalty to individuals seen traveling with unrestrained children. This has been shown to be effective in the US where enforcement of booster seat law at checkpoints and issuance of tickets to defaulters in Delaware, New Jersey, Pennsylvania and Washington significantly increased compliance to the use of CCRs among drivers. ${ }^{25}$

\section{Acknowledgments}

The authors of this work wish to acknowledge the management and staff of the schools Froebel, Graceland, Spring of Life, Pine Crest, Carlton Duke and Evergreen, whose students participated in the study. They also appreciate the efforts of Ms Oko Amara Jennifer, the trained research assistant, in collecting and organizing all the completed and returned questionnaires from the different schools.

\section{Author contributions}

This work was carried out in collaboration between all authors. Authors KIN and UE conceived the study. KIN, UE, and DCO did the study design and wrote the protocol. DCO did the data analysis and wrote the result section. All authors contributed toward data analysis, drafting and critically revising the paper and agree to be accountable for all aspects of the work.

\section{Disclosure}

The authors report no conflicts of interest in this work.

\section{References}

1. World Health Organization. Module 1: The Need for Seat-Belts and Child Restraints. Available from: http://www.who.int/roadsafety/ projects/manuals/seatbelt/seat_belt_manual_module_1.pdf. Accessed September 23, 2016.

2. Hipolite TT. Motor traffic injuries in Sub-Saharan Africa. DMSJ. 2012;19:13-16.

3. WHO. Global Burden of Disease 2004 updates. 2004. Available from: http://www.who.int/violence_injury_prevention/en/. Accessed October 10, 2016.

4. Olumuyiwa JO, Adeleke OI, Sylvester AA, Samuel OO. The impact of seat-belts in limiting the severity of injuries in patients presenting to a university hospital in the developing world. Niger Med J. 2013;54(1):17-21.

5. Greenwall NK. Results of the National Child Restraint Use Special Study. Washington, DC: National Highway Traffic Safety Administration; 2015:66.

6. Road Safety Observatory. Seat belt? How effective. 2015. Data from Sweden, USA and the Great Britain. Available from: http://www. roadsafetyobservatory.com/Summary/vehicles/seat-belts. Accessed October 10, 2016.

7. Osifor OD, Osagie TO, Iribhogbe PE. Paediatric road traffic accident deaths presenting to a Nigerian referral center. Prehosp Disaster Med. 2012;27(2):136-141.

8. Peden M, Scurfield R, Sleet D, et al., editors. World Report on Road Traffic Injury Prevention. Geneva: World Health Organisation Report; 2004.

9. Tavafian SS, Aghamolaei T, Gregory D, Madani A. Prediction of seat belt use among Iranian automobile drivers: application of the theory of planned behavior and the health belief model. Traffic Inj Prev. 2011;12(1):48-53.

10. Cook LJ, Hoggins JL, Olson LM. Observed seatbelt usage among drivers of heavy commercial vehicles in Utah. Accid Anal Prev. 2008;40(4):1300-1304.

11. Begg DJ, Langley DJ. Seat-belt use and related behavior among young adults. $J$ Safety Res. 2000;31:211-220.

12. Wikipedia, the Free Encyclopedia [webpage on the Internet]. Enugu. Available from: http://en.wikipedia.org/wiki/Enugu. Accessed September 23, 2016.

13. Nigerian Population Commission. State and Local Government Demographic Profile: 1991-2010. Abuja: Nigerian Population Commission; 2011.

14. Oyedeji GA. Socioeconomic and cultural background of hospitalized children in Ilesa, Nigeria. Niger J Paediatr. 1985;12(4):111-117.

15. Yanchar NL, Kirkland SA, LeBlanc JC, Langille DB. Discrepancies between knowledge and practice of childhood motor vehicle occupant safety in Nova Scotia: a population-based study. Accid Anal Prev. 2012;45:326-333.

16. Durbin DR. Technical report - child passenger safety. Pediatrics. 2011;127(4):e1050-e1066. Advance online publication 2014.

17. Arbogast KB, Jermakian JS, Kallan MJ, Durbin DR. Effectiveness of belt positioning booster seats: an updated assessment. Pediatrics. 2009;124(5):1281-1286.

18. OECD Publishing. Nigeria, in Road Safety Annual Report 2014. Paris: OECD Publishing; 2014.

19. CDC [webpage on the Internet]. Child Passenger Safety: Buckle Up Every Age, Every Trip. 2014. Available from: http://www.cdc.gov/ vitalsigns/childpassengersafety/. Accessed September 23, 2016.

20. Chen X, Yang J, Peek-Asa C, McGehee DV, Li L. Parents' knowledge, attitude, and use of child restraints, Shantou, China. Am J Prev Med. 2014;46(1):85-88.

21. Olufunlayo TF, Odeyemi KA, Ogunnowo BE, Onajole AT, Oyediran MA. An observational survey of child car safety practices in private preprimary and primary schools in two local government areas of Lagos State, Nigeria. Inj Prev. 2012;18:216-220. 
22. Federal Road Safety Corps [webpage on the Internet]. Offences \& Penalties. 2016. Available from: http://frsc.gov.ng/offences-and-penalties. Accessed September 23, 2016.

23. Ukoji VN. Trends and Patterns of Fatal Road Accidents in Nigeria (2006-2014). IFRA-Nigeria e-papers series; 2014. Available from: http://www.ifra-nigeria.org/IMG/pdf/fatal-road-accidents-nigeria.pdf. Accessed September 23, 2016.
24. National Highway Traffic Safety Administration. Motor Vehicle Safety Occupant Survey. Vol. 5. Washington, DC: US Department of Transportation; 1998:31.

25. National Highway Traffic Safety Administration. Booster Seat Law Enforcement Examples from Delaware, New Jersey, Pennsylvania, and Washington. Washington, DC: US Department of Transportation; 2007:1-67.

\section{Publish your work in this journal}

Pediatric Health, Medicine and Therapeutics is an international, peerreviewed, open access journal publishing original research, reports, editorials, reviews and commentaries. All aspects of health maintenance, preventative measures and disease treatment interventions are addressed within the journal. Practitioners from all disciplines are invited to submit their work as well as healthcare researchers and patient support groups. The manuscript management system is completely online and includes a very quick and fair peer-review system. Visit http://www.dovepress.com/ testimonials.php to read real quotes from published authors. 